\title{
When Your "Problem" Becomes Mine: Adult Female Siblings" Perspectives of Having a Brother with a Disability
}

\author{
Michelle N. Pompeo \\ The University of Western Ontario
}

\begin{abstract}
This study is a retrospective look at adult female siblings' perspectives of their childhoods and present identities based on having a brother with a disability. This paper focuses on siblings' experiences within educational and public domains, and how such experiences have shaped their personalities and career choices. Qualitative findings were organized into four central themes, each with subcategories: (a) Siblings' Fear and Worries, in-school bullying, school friends coming to the home; (b) Anger and Resentment, towards the perceived advantages of having a disability, towards teachers; (c) Positive Impacts, acceptance of others in varied public contexts, advocacy; and (d) Career Choices, entering the teaching profession. Findings are discussed in relation to both the emotional and educational significance for siblings.
\end{abstract}

Until the early 1980s, research on the sibling perspective was almost non-existent (Brody \& Stoneman, 1993; Stoneman, 2005). Work from 1980 until the early 1990s focused on how siblings were "affected" by their brother or sister with disabilities (Featherstone, 1980; Grossman, 1972; Seligman \& Darling, 1989). While these works were helpful in describing the feelings some young siblings had, the siblings' perspective was often presented as a side issue and not the main focus of analysis. Other work in this period tended to focus on teacher and mother appraisals of the young siblings' adjustment and was therefore predominantly quantitative (Stoneman, 2005). There was a need to further investigate the siblings' perspective about past and present educational experiences by asking siblings directly to reflect on such experiences.

Studies on the long term effects of having a brother with a disability have been emerging (e.g., Dyson, 1999; Lardieri, Blacher, \& Swanson, 2000), but they focused on the sibling pair during childhood (Stoneman, 2005; Stoneman \& Berman, 1993). While important, there re- 
mained a need to understand how such experiences affect siblings across the life course (Azeez, 2002; Flaton, 2006; Seltzer, Greenberg, Orsmond, \& Lounds, 2005). The purpose of this study was to discover the adult sibling perspective of her life to date-in early adulthood. The researcher wanted to know how adult female siblings of people with disabilities feel their sibling influenced the course of their lives within public domains, such as school, in the past and present. Data arising from adult perspectives is useful for creating further understanding about sibling standpoints and for informing educators about a unique and often silent population.

\section{Theoretical Frameworks}

Social ecology/ecological psychology, family systems theory, labeling theory, and the social model of disability were the guiding theories the researcher used to conceptualize adult female siblings' perspectives. Such theoretical orientations allowed the researcher to understand the sibling as being individually influenced by her sibling with disabilities, as part of a family with disability, and therefore considered different in social contexts.

Social ecology. As in natural ecology, social ecologists believe that a change in any part of the ecological system affects subparts of that system, creating the need for system adaptation or equilibrium (Seligman \& Darling, 1989). It was not until Bronfenbrenner's (1979) theory that the family was considered to be a system in itself that would influence the child and be influenced by the child (Seligman \& Darling, 1989). Mitchell's (1983) study applied Bronfenbrenner's theory (i.e., the interdependent relationship of each family member's effect on the other) to studying families who have children with disabilities (Bronfenbrenner, 1979). For the purposes of this study, this theory was used to understand how the sibling with disabilities influences the sibling without disabilities. From within this framework, it is understood that the immediate family is considered the most important influence on a child, while the school is the second most important influence (Bronfenbrenner, 1979).

Family systems theory. This theory is consistent with the previously mentioned theory; however, its focus is on the family. The main idea is that anything that happens to one family member affects the other members. Furthermore, to understand better what is going on in the life of one member, one should be equipped with knowledge about the rest of the family members (Seligman \& Darling, 1989). This holistic approach considers how personal variables influence the individual family unit. This theory is useful in considering how the child with disabilities influences the other sibling and how the sibling influences the child with disabilities.

Labeling theory. Labeling theory recognizes that people become or act according to their label (Gill \& Maynard, 1995). It also recognizes that what was considered "deviant" behaviour was socially constructed. Thus, it is society that creates labels, terms, diagnoses, and categorizations that are perpetuated by discursive practices. It also addresses how the labeled person experiences stigmatization resulting from the assigned label and how labels influence access and denial to resources and programs (Gill \& Maynard, 1995). Further, it considers how the continued use of a specific label is limiting since stereotypical images or thoughts are automatically conjured when the term is used, rather than considering the person first. For those who have more than one type of disability, labeling becomes even more problematic. This theory was 
used to determine the possible effects of the label (i.e., its diagnosis, understanding) on the sibling relationship.

The social model of disability. The social model is a way of conceptualizing disability in society. It was the first framework to recognize that it is society that is disabling, not the actual disability itself (Barnes, 1998). Work by Finkelstein (1980) showed that employment for people with disabilities depended entirely on the historical period in which they lived (Barnes, 1998). Thus, if people in the community with disabilities lived during the feudal period, they could often find work. Those living in the time of industrialization were likely unable to find work and therefore forced to live in institutions because they could not afford regular housing (Barnes, 1998). This work demonstrates that constant shifts of values and ideologies are occurring over time.

For the purposes of this study, the social model is valuable in that (a) it emerged from people with disabilities themselves, (b) it roots the problems in attitudinal and physical barriers, and (c) it provides an alternative to an over-reliance on traditional medical perspectives (Barnes, 1998). Barnes also outlined the deficit and medical models of conceptualizing disability. The deficit model is the most negative, wherein the person with a disability is viewed as missing something and therefore not fully complete. The medical model is less negative than the deficit model, but it focuses entirely on how to best fix or remedy the "problem" within the person. The social model focuses not on trying to fix, or one might argue "normalize," but rather on attitudinal and physical barriers towards people with disabilities and their families in differing social contexts.

The above noted theories are applied to how stigmatization occurs for the sibling through a process of secondary stigmatization (Goffman, 1986). The idea is that the entire family becomes labeled as a "disabled family" or a "family with disabilities" (Michalko, 2002). It has also been suggested that a family with disabilities is held in common with other families in a similar situation and this creates a notion of "social suffering" (Michalko, 2002). For the purposes of this study, this notion of suffering applies to all families with children with disabilities, acknowledging that despite the specific disability diagnosis, feeling othered in social settings repeatedly occurred in differing social contexts throughout the siblings' lives.

\section{Method}

\section{Participants}

Five female siblings of brothers with disabilities, between the ages of 22-25 years and having at least one brother with a disability responded to a semi-structured interview. Participants were Caucasian and had attended a post-secondary institution. All but one sibling had completed an undergraduate degree at a Canadian university. The sibling who did not complete an undergraduate degree completed a college degree at a Canadian college. The women came from both Jewish and Christian religious backgrounds and were a minimum of second generation (maximum of $3^{\text {rd }}$ or $4^{\text {th }}$ generation) Canadian. Four of the women attended public schooling in Ontario and one woman attended a private school. None of the women were married or had children. At the time of the interview, all five participants lived in their parents' homes; four women had their brother with a disability also living in the same home. All but one family con- 
sisted of two biological parents who were married and still together at the time of the interview. One sibling had parents who separated when she was a child.

The participants were contacted through social networking, as recruitment for studies of sensitive subject matter of this kind tends to be difficult. The original call for participants was open to both female and male siblings, with either brothers or sisters with disabilities, but only women (with brothers with a disability) were recommended through networking.

To respect the confidentiality of participants, pseudonyms were created. If quoted directly, the participants in this study were given the following pseudonyms: Jennifer (participant 1), Sharon (participant 2), Natalie (participant 3), Amy (participant 4), and Sabrina (participant 5). The sibling without a disability was referred to, generally, as "participant." The sibling with disabilities was referred to as "brother." The word "problem" is used in the title of the work and it is in quotes to indicate that the siblings' with disabilities were often viewed to be problematic by those outside of the immediate family.

\section{Procedure}

After informed consent was given, interviews took place in casual settings of convenience to the participants - often in participants' homes. The author interviewed all of the women in person. Twenty-eight semi-structured interview questions were designed to capture participants' retrospective accounts of their experiences being related to an immediate family member with disabilities. This work focused on the educational and other public domain responses (see Appendix). Interview questions were formed from four themes that appeared across the literature: (a) siblings' fears and worries, (b) anger and resentment, (c) positive impacts, and (d) career choices (Connors \& Stalker, 2003; Darling, 1987; Featherstone, 1980; Meyer \& Vadasy, 1994). Participant responses were examined and led to the creation of the corresponding subcategories within each of the four major themes (see Results).

Interview length varied from 45-120 minutes depending on the participant; three of the interviews were 60 minutes. All interviews were audio taped, transcribed verbatim, and identifying information was removed in order to protect the identity of the participants. In addition to audio taping, informal notes were jotted down where appropriate to provide information about key terms, questions, or comments needing clarification at the end of the interview.

Many labels were referenced in this study. In keeping consistent with labeling theory, it is important to note that this was the participant's account of how her brother was labeled in a given context. The disability labels familiar to the sibling were based on diagnoses and labeling that occurred in the early to mid 1980s. It is not necessary to provide a medical definition for the purposes of this study but to further clarify what these abbreviations represent. It is up to the reader to seek more information about the labels, if so desired. The labels referred to were Attention Deficit Disorder (ADD), Attention Deficit Hyperactivity Disorder (ADHD), Obsessive Compulsive Disorder (OCD), Tics, Down syndrome, Dyslexia, physical disability due to an accident, and Learning Disability (LD). In some cases, brothers had a combination of these labels. The labels only mattered in relation to how the siblings felt about this label. It should be noted that Down syndrome is not a learning disability. 


\section{Data Analysis}

Data analysis consisted of three concurrent flows of activity: data reduction, data display, and conclusion drawing/verification (Miles \& Huberman, 1994). Reducing and condensing data was ongoing as the study progressed. After the interview data were transcribed verbatim, they were scanned and then re-read. Then, a constant comparison method was used to categorize or code the interview responses. Thus, data was continually examined for examples of similar cases and patterns, as well as different or divergent cases. Reoccurring participant responses (Miles \& Huberman, 1994) yielded subcategories (see Results). Responses were then compared to each other and to the relevant literature so that data analysis was constantly woven into the interpretation and write up of the study.

This qualitative study, therefore, employed the social anthropology approach to analyzing data (Miles \& Huberman, 1994). This approach permitted detailed and rich descriptions across cases to emerge. Social anthropologists focus on "individuals' perspectives and interpretations of their world" and are interested in the behavioural regularities of everyday life, such as relationships (Miles \& Huberman, 1994, p. 8). While the primary methodology used by social anthropologists is ethnography, "researchers in ecological psychology, narrative studies, and in a wide range of applied studies (education...family studies) often take this general line" (Miles \& Huberman, 1994, p. 9). This approach was an appropriate stance for gathering information about siblings' perspectives of their lives in public domains.

The conceptual lenses through which the researcher viewed participants' responses were from within the traditions of social ecology/ecological psychology (Bronfenbrenner, 1979) and sociology (social model, labeling theory); therefore, data display occurred in the form of the personal narratives of siblings' retrospective accounts of their lives in a family with disability (Michalko, 2002).

\section{Results}

The following findings are organized according to four central themes and subcategories.

\section{Siblings' Fears and Worries}

In-school bullying. When looking back at their childhoods, almost all participants reported that they feared or were worried about in-school bullying or teasing. The three that went to school with their siblings reported that teasing was harsh and prevalent. Those who did not go to the same school as their brothers-because their brothers eventually went to a more specialized school or a private school-commented that they knew teasing was going on and were glad they did not see it because it would have upset them. Thus, participants not attending the same school still worried about bullying they could not directly observe. It is important to note that participants reported bullying occurring in the early 1980s, which was prior to the recent rise in anti-bullying research and awareness now present in Canadian schools. Sabrina recalled an example of bullying that had serious ramifications:

He got his arm broken by a school bully one year. And the school was horrible. I remember being 12 or 13 and fighting with the teachers, having to pick him up from school, and they're just like, "Oh, you can't do this; you can't do that." Even teachers, like surprisingly enough, you end up ar- 
guing with them. He doesn't really get teased nowadays. Just, you know, the usual school bullies and of course, I was around. Whenever I was there, I would stand up for him, be the big sister. I still do.

Participants dealt with a serious level of in-school bullying. They found some teachers and principals were unsupportive and inattentive to the possibilities of school violence and danger. Siblings may encounter an unfavourable school environment in general since teachers may judge them according to their siblings and hold lower expectations of them academically (Dyson, 1996). All but one participant worried about their brothers being bullied at school for having a disability. The other participant, Sharon, noted that her brother was not teased in school but that he was the "class clown." His hyperactivity made him more likable, but he was often "goofing off" and getting suspended.

School friends coming to the home. Three participants felt nervous about how their school aged friends would react when they came into contact with their brothers for the first time. They would warn people about the disability beforehand or make a joke about it. Every time a new person entered the home, across various life stages, the participants would worry about how the social function would unfold. A common internal question for participants before a social gathering was reported: Would anyone say anything upsetting, politically incorrect, or ask any embarrassing questions? As Jennifer recalled as a teenager,

If I'd be having a party, I'd be like, "Oh, my brother is going to be around. He's a little weird, sometimes he does weird things" "He might wash his hands a few too many times. What an idiot!" You know, make a joke out of it, even though it might not have been fair. I'm doing exactly what I don't like people doing.

Other participants were not at all worried about their brothers before a social function. As Sabrina recalled (angry),

I was never bothered by it. I don't know what it is like to have a normal sibling, so I never thought twice about it. Like, whatever, here's my brother, here's my house. I mean, the only reason I didn't like people over was, for a long time, our house wasn't decorated. The curtains were ugly. People always ask, you know, "What is it like having a handicapped brother?" Well, I don't know because to me, it's normal, so I don't know. Come on over; let's hang out. Who cares?

This quote demonstrates what a lot of participants go through before the "going public" phasethe phase when the family faces society and realizes they are "different" according to societal standards of normalcy, the family that had always been normal to them because that is all they know (Seligman \& Darling, 1989). At first, they are not bothered by the disability, but society tends to be, and so they become upset by what the outside world thinks about them and their brother because it influences how they are treated. One participant warned others to protect both the brother's and parents' feelings. Then, in her mind, there is less of a chance of people saying anything and less of a shock value when they do come into contact with the brother for the first time. The warning, she indicated, was her coping mechanism and a way of protecting her brother and family. 


\section{Anger and Resentment}

In public contexts, such as school or extracurricular activities, a brother's disability stigmatizes him as different. Inside the family, however, each child wants to be special. So, while it is good for the child with disabilities to be a unique part of the family, the other child may not feel as special and become jealous and resentful (Featherstone, 1980). Participants recalled from a young age being angry at their familial situation due to frustration. When asked to describe their childhood, many participants reported that it was difficult. All participants, except one, reported feeling negativity - anger, frustration, and resentment - towards the extra attention their brother was receiving. Even though they realized he needed it, they still felt angry or left out. Similarly, in her childhood, Natalie remembered feeling a little jealous that her brother got to go off to a special education class. Only one participant recalled feeling happy for her brother that he was receiving extra attention at school. Amy said, "Great. He deserves it."

The advantage of having a disability. All participants in the study felt that their brothers used their disability to their advantage. However, they interpreted the word advantage differently. One participant felt the disability itself (i.e., ADHD) to be advantageous because it made her brother hyper, appealing, upbeat, and able to land deals in the business world. For this participant, the disability afforded her brother financial success as a senior executive in a computer software company. According to Sharon,

They put him on Ritalin and it made him so calm that he couldn't perform at his job. Cause that's what made him the money, that's what got him the sales, cause he's so hyper, so outgoing, that when he would talk to sales people, they loved him and he would land the accounts. He had to go off the Ritalin.

This participant clearly had a positive view of the effects of her brother's disability and her brother without prescribed medication. However, other participants do not remember being as positive as children. Two participants felt that their brothers' labels were easier routes to getting special advantages, instead of realizing that school was exceptionally difficult for the brother because of certain barriers he faced. Amy said her brother's physical disability (i.e., losing three fingers on his hand and losing the ability to write) is "not that bad of a disability" and that he plays it up in order to have things easier. According to Amy,

OH GOD, yeah. Are you kidding me? Oh God (laugh) for school, oh for so many things. To get his way into having two more hours to write his exam because of his disability, when we all know it's not really THAT bad of a disability.

Childhood anger was a common feeling among participants in this study. It manifested itself in different ways for each participant — anger towards the brother with disabilities or teachers.

Towards teachers and schools. Participants recalled their earlier school years as full of turmoil for themselves, their brothers, and their parents. For most of them, school was the place where the "problem" with the brother with disabilities was amplified. As Jennifer recalled,

Well, they (parents and brothers) had to do private testing because the school was taking too long because they couldn't figure out what was wrong him, and so for years and years and years, he bounced from school to school and was a problem in the home and in the school and we didn't understand why, and so finally my parents broke down and went to a private testing place. 
Similarly, Sharon reported the same testing method for determining a label:

He was going for testing to find out what was wrong because he was having attention problems at school. So, he went to, I forget the name of it, a place to get testing and that's when my mom told us he had ADHD. It was because he was having a lot of problems at school and the teachers, obviously, weren't being very supportive. He would get suspended all the time, so that's when my mother got him tested, and he actually has a very high IQ.

For participants of brothers with non-physical disabilities, school was the first public place that created the need for a label. It was also the place where the brother with disabilities did not secure a permanent position in the school. Again, participants reported on their experiences that took place in the 1980s in Ontario - a time when integration characterized schooling practice (Ainscow \& César, 2006). This meant that in order for children to receive additional resources, they had to have been labeled (Ainscow \& César, 2006). This might account for why some participants in the study remember the pressing need for their families to find the root cause of their brothers' "problem" and to secure a label in a timely fashion.

\section{Positive Impacts}

Acceptance. Participants reported that because they had a brother with a disability, it made them more accepting of others who were considered "different" in society and more openminded. In Flaton's (2006) case study, the female sibling considered herself more empathetic to people in general because of her brother with Down syndrome. In the discussion section, Flaton cautioned the reader against interpreting this with too much stock. Flaton asked whether the sibling really could experience an increase in an individual's ability to empathize with less fortunate people or if this was merely her perception. This is not an easy question to answer, but all participants in this study found themselves giving people the "benefit of the doubt," as one participant indicated, or almost gravitating towards a person with a disability in a new group so as not to make them feel alone or left out. According to Amy,

I think I'm very open-minded now, where I sort of accept everyone the way they are. But I tend to, if I see someone who has a disability, I gear more towards that person. I just want to talk to them and let them feel that someone would talk to them because I was always scared that Mike would never find a girlfriend.

Other participants reported being accepting of others and allowing this acceptance to influence their actions towards other friends with disabilities in school settings as well. According to Jennifer,

I had a friend in University, when I was there as well and he was trying to do law, but he had an LD, he had dyslexia; the same thing my brother has, and any time the professor would jump on him with a question and he stuttered, I would help him out because I know what it's like. He told me that I helped him out, and he was grateful. I understand that when you ask them a question, they might have the perfect answer in their head, but they have a tough time getting it out.

This participant, therefore, considered herself accepting of all types of people and free from discriminating against others. Similarly, the female participants in McGraw and Walker's (2007) work reported a greater sense of empathy and personal growth because of their sibling with a disability. Also, they found themselves helping people at the more local level in situations where 
others would not offer assistance. Participants in this study were aware of their heightened sense of perception and sensitivity towards others, and some of them found it difficult when acceptance of their brothers was not necessarily reciprocated by others. As Jennifer pointed out,

You know people don't understand because he looks normal and he's highly intelligent, but it is still hard for him. "Why can't he just act normal?" "Why can't he just get a job?" "Why can't he just go to school?" He CAN'T do it right now! He CAN'T do it! Just accept it!

This participant was angered by the societal creation of what she termed the "traditional time line" that many people with or without disabilities feel pressured into (e.g., go to school, get a job, get married, and have children). As literature in this area indicates, the traditional milestones celebrated in one's life are times that parents - and participants in this case - are reminded by others of the brother's inability to fit into societal standards of normalcy (Lobato, 1990).

Tolerance and patience. Some participants reported that having a brother with a disability has made them more tolerant, perhaps more tolerant than other people who do not live with children with hyperactivity disorders. As Sharon explained,

There is this guy from work that tried to come from behind and scare me, but I didn't even flinch. He's like "Oh, my God. What, you have no reflexes?" And I'm like "No, I have a brother with ADHD."

All participants, when asked about advocating for disability rights, strongly indicated that they have spoken up to support a stranger who was being picked on or admonished someone who illegally parked in a wheelchair spot. They also reported correcting people's inappropriate language or terminology when speaking of or to a person with a disability. As Jennifer expressed, "Anytime I heard someone making fun of someone, calling them retarded or picking on kids who are slower or whatever, I'm the kind of person who always gets involved." Sharon also expressed the same type of reactions to everyday occurrences where someone with disabilities was being picked on. Another participant, Amy, claimed that she had not seen teasing in her adulthood, but she still reacted in the same manner as the other participants if she was to come across a situation where a person was being made fun of or mistreated due to having a disability. Participants also desired change to occur in social institutions and interactions. They felt that attitudes have to change in the local community, not so much by outsiders but by "people who know." Participants defined this as people who have family members or friends with disabilities. Participants felt that "people who know" should come out and discuss their experiences more.

\section{Career Choices}

Another finding consistent with the literature was that four of the five women were in, or were in training for, the "care professions" (Seligman \& Darling, 1989). A new aspect of this finding, however, was that three women were in preservice preparation programs in Ontario to become certified teachers - an interest, they believe, stemmed directly from their negative school experiences with unsupportive teachers (see "in school bullying") and students in relation to how those groups treated their brothers with disabilities. They also wished to be positive influences in schools for the next generation of families with disabilities. Brody and Stoneman (1993) found similar results in children based on observing their play: older female siblings assumed teacher or manager positions when interacting with their younger brother with a disability. However, it 
should not be assumed that all siblings of children with disabilities will automatically choose care professions. There have been cases where the opposite is true (Seligman \& Darling, 1989); some siblings adopt the attitude that they have served their time or have given their fair share in terms of caring and responsibilities and may deliberately seek fulfillment in careers outside of the helping professions. One sibling in this study was pursuing journalism, a career outside of the traditionally defined care professions.

\section{Discussion}

It is imperative that the sibling perspective of the particular "family with disabilities" continues to be encouraged in future work in addition to other methods of reporting. Narrative data arising from the present group has indicated that young siblings often lack an adequate understanding of why their sibling is acting as he is or receiving differential treatment or attention at school. They were, therefore, often confused, silent, and hurt as young children, but excellent at concealing this conflict to protect their families and their siblings.

Siblings conceptualize their brothers with disabilities, and therefore themselves, based on family systems theory, to be within the deficit model while attending school. Testimonials indicate that school was often a traumatic place for siblings and they experienced a lot of anxiety and worry about attending school due to teachers' perceptions of their sibling with disabilitiesand themselves by association - and bullying. Thus, negative ways of thinking about their brothers and themselves were due to the degree of acceptance they felt within a specific social context. Some teachers were positive, while others were not. Some friends were accepting, while others were shocked or had to be forewarned before coming over.

Young siblings sometimes exhibit problematic or aggressive behaviour at school, such as resisting teachers or other students, particularly if those students are bullying their siblings with disabilities during unsupervised times. One suggestion is to inform teachers and other school professionals of the sibling's familial situation and resulting obligations. Such awareness might foster a better understanding of some of the conflicting emotions young siblings may be experiencing and exhibiting at school.

Further, well-informed teachers might be able to provide the sibling with some type of understanding about the disability where it may be lacking at home because parents are working and coping with handling the disability diagnosis for the first time. The teacher is crucial in modeling inclusive social practices in the classroom, something the sibling without disabilities, and arguably all children, may benefit from observing. However, such disclosures are contextspecific and depend on the family with disabilities and the relationship the family has with the particular school. Siblings may not want extra attention directed at them in this regard because they might not feel "different" at all (see Sabrina's response, "school friends coming to the house"). Conversely, siblings might appreciate some teacher awareness to help accommodate experiences of bullying (see Sabrina's response, "in school bullying").

While the adult sibling perspective provides valuable insight to the changing nature of sibling relationships, researchers have to rely on the memory of the sibling alone when trying to understand the childhood and adolescent phases of development. It has been argued that this may prove to be beneficial, however, since adults possess greater self-knowledge (Flaton, 2006) than do children or adolescents. Flaton pointed out that adults are often able to reflect on their experiences with a fuller understanding of how having a sibling with disabilities had an impact on the context of their own development throughout childhood and adulthood. 
Stoneman (2005) noted that a homogenous sampling population needs to be considered when research is designed. Therefore, future work on siblings should employ a sample that is as homogenous as possible in terms of race, SES, age, gender (Seltzer et al., 2005), level of education of the siblings without disabilities, ordinal position in the family, relationship of the sex of the siblings to the child with disabilities (i.e., male-male, male-female, female-male, femalefemale) must be simultaneously considered (Stoneman, 2005), the type and severity of the disability, family size, level of education of parents, exhibited stress of parents (Dyson, 1999), cultural and religious beliefs, and ensure control groups of a normative sample of typically developing children are also included (Stoneman, 2005). This study addresses the majority of such recommendations. Specifically, it considers how the female-male sibling relationship over the life span has influenced the participants' educational experiences to the present. Further, participants are all from an age range of early adulthood, from similar SES backgrounds in Ontario, and attended public school.

This study, however, did not keep the disability diagnosis constant, nor did it employ a control group, and it covered a wide range of disability diagnoses. This study was interested in discovering the social experiences that siblings encountered in public spheres, not to rank or categorize experiences based on disability diagnoses alone. This study cannot be generalized to the larger population and future studies might want to consider employing larger sampling populations. Future studies might compare the findings to male-male sibling relationships over the life span and consider differences in the gendered nature of these relationships.

This study addressed the need to investigate what adult female siblings, in a Canadian context, encountered throughout various stages of the life cycle in pubic domains such as in school, work, and university settings. By asking siblings to directly reflect on their lives, the sibling voice was included in an effort to create further understanding about the public experiences of an often silent group of individuals.

\section{References}

Ainscow, M., \& César, M. (2006). Inclusive education ten years after Salamanca: Setting the agenda. $E u$ ropean Journal of Psychology of Education, 3, 231-238.

Azeez, C. C. (2002). Siblings of people with disabilities: A developmental analysis of the effects, impacts, and patterns of adaptation. Dissertation Abstracts International, 62(9), 3200A.

Barnes, C. (1998). The social model of disability: A sociological phenomenon ignored by sociologists? In T. Shakespeare (Ed.), The disability reader: Social science perspectives (pp. 65-78). London: Redwood Books.

Bateman, K. A. (2004). Retrospective reports of family experience as siblings of individuals with physical difficulties. Dissertation Abstracts International, 65(5-B).

Brody, G. H., \& Stoneman, Z. (1993). Parameters for inclusion in studies on sibling relationships. In Z. Stoneman \& W. Berman (Eds.), The effects of mental retardation, disability, and illness on sibling relationships (pp. 275-286). Baltimore: Brookes.

Bronfenbrenner, U. (1979). The ecology of human development. Cambridge, MA: Harvard University Press.

Connors, C., \& Stalker, K. (2003). The views and experiences of disabled children and their siblings: A positive outlook. London: Jessica Kingsley Publishers Ltd.

Cuskelly, M., \& Harland, P. (2000). The responsibilities of adult siblings of adults with dual sensory impairments. International Journal of Disability, Development and Education, 47, 293-307. 
Dyson, L. (1999). The psychosocial functioning of school-age children who have siblings with developmental disabilities: Change and stability over time. Journal of Applied Developmental Psychology, 20, 253-271.

Featherstone, H. (1980). A difference in the family: Life with a disabled child. New York: Basic Books.

Finkelstein, V. (1980). Attitudes and disabled people: Issues for discussion. New York: World Rehabilitation Fund.

Flaton, R. (2006). "Who would I be without Danny?" Phenomenological case study of an adult sibling. Mental Retardation, 44, 135-144.

Gill, V., \& Maynard, D. (1995). On "labeling" in actual interaction: Delivering and receiving diagnoses of developmental disabilities. Social Problems, 42, 11-30.

Goffman, E. (1986). Stigma: Notes on the management of spoiled identity. New York: Simon \& Schuster.

Grossman, F. K. (1972). Brothers and sisters of retarded children: An exploratory study. Syracuse, NY: Syracuse University Press.

Lardieri, L. A., Blacher, J. A., \& Swanson, H. L. (2000). Sibling relationships and parent stress in families of children with and without learning disabilities. Learning Disability Quarterly, 23, 106116.

Lobato, D. J. (1990). Brothers, sisters and special needs. Baltimore: Paul H. Brookes Publishing Company, Ltd.

McGraw, L., \& Walker, A. (2007). Meanings of sisterhood and developmental disability: Narratives from white nondisabled sisters. Journal of Family Issues, 28, 473-500.

Michalko, R. (2002). The difference that disability makes. Philadelphia: Temple University Press.

Miles, M., \& Huberman, M. (1994). Qualitative data analysis (2nd ed.). Thousand Oaks, CA: Sage Publications.

Mitchell, D. (1983). Guidance needs and counseling of parents of mentally retarded persons. In N. N. Singh \& K. M. Wilton (Eds.), Mental retardation: Research and services in New Zealand. Christchurch, New Zealand: Whitoculls.

Seligman, M., \& Darling, R. (1989). Ordinary families, special children: A systems approach to childhood disability. New York: The Guilford Press.

Seltzer, M., Greenberg, J., Orsmond, G., \& Lounds, J. (2005). Life course studies of siblings of individuals with developmental disabilities. Mental Retardation, 43, 354-359.

Stoneman, Z. (2005). Siblings of children with disabilities: Research themes. Mental Retardation, 43, $339-350$.

Stoneman, Z., \& Berman, P. W. (Eds.). (1993). The effects of mental retardation, disability, and illness on sibling relationships: Research issues and challenges. Baltimore: Brookes.

\section{Author's Note}

Correspondence concerning this article should be addressed to Michelle N. Pompeo, 1137 Western Road, London, ON, Canada, N6G1G7. Email: mpompeo@uwo.ca

I would like to thank my supervisor, Dr. Carolyn Ewoldt, and my advisor, Dr. Isabel Killoran, from York University. 


\section{Appendix}

Key Questions

1. What are some of the emotions siblings felt, as children, regarding their brother or sister with disabilities?

2. How did the sibling find out that his/her brother or sister had a disability? Did this occur in the public sphere such as school, or did it occur in a private setting such as the home?

3. How old was the sibling when he/she found out there was something "different" about the brother or sister? Does the sibling remember the first time he/she found out, and was this a positive or negative experience?

4. If the sibling ever had any questions or concerns throughout childhood about his/hers brother or sister, whom did they seek out for answers? Or, did they not ask any questions at all?

5. Was the sibling ever present when his/her brother or sister was teased at school? If so, who was the person doing the teasing?

6. Can the sibling describe what his/her childhood was like?

7. Can the sibling describe a time when his/her sibling used the disability to an advantage?

8. How did the sibling feel about the extra attention the child with disabilities was receiving?

9. How does the sibling feel about advocating for disability rights?

10. Has the sibling heard any language against people with disabilities? What is the reaction?

11. Has the sibling ever witnessed inappropriate behaviour (by societal standards) of his or her brother/sister in public? How did this make the sibling feel?

12. How did the sibling feel when a new person came to the home? Why? 